\title{
Investigating the effect of ecommerce on export development of rose water and essences
}

\author{
Ali Nataghi ${ }^{\mathrm{a}}$ and Ali Baghi Nasrabadi ${ }^{\mathrm{b} *}$
}

${ }^{a}$ Department of Management, Naraq Branch, Islamic Azad University (IAU), Naraq, Iran

${ }^{b}$ Assistant Professor \& Faculty Member, The Institute of Imam Sadiq (AS), Qom, Iran

\section{H R O N I C L E}

\section{Article history:}

Received June 4, 2014

Accepted 29 October 2014

Available online

October 312014

\section{Rose water}

Essences extract

Export

Information barriers

Kashan \begin{abstract}
A B S T R A C T
There are some issues in marketing, supply and after-sales services for customers in global markets for production of rose water and essences extracts. Despite the fact that the products are genuine, there is a downward trend for the production of rose water and essences extracts in recent years. The present study aims to evaluate the identified structural barriers affecting exports of rose water and essences of Kashan to United Arabic Emirates. The population consisted of 77 managers of exporter companies in Kashan. Self-made questionnaire approved by supervisor to be valid and reliable, were distributed. The study tried to deliver a model for barriers to e-commerce in the context of Iran's rose water and essences extracts Export by examining different models of and studied in the field of electronic commerce and the application and advantages of systems based on it. The study also tried to identify current obstacles in the way of electronic commerce in export of rose water and essences extracts by using the questionnaire as an indicator in five-point Likert scale. There were three factors associated with the proposed model. Barriers to electronic commerce in export of rose water and essences extracts were determined in the order of priority as follows:

1) Problems and obstacles related to information infrastructure, 2) problems related to legislative, legal and secure infrastructure, 3) problems and obstacles to human, educational, cultural and behavioral infrastructure, 4) problems related to infrastructure of customs, trade and taxation, 5) internet problem, 6) Problems related to technical and hardware infrastructure, 7) Problems related to financial and software infrastructure.
\end{abstract}

\section{Introduction}

The developments in the last century, the late twentieth $\mathrm{AD}$, were unprecedented in the history of science and technology; because the Industrial Revolution and electronic transmission were mixed with the development of information technology to create Information and Communication Technology (ICT) (Kiley, 1999). ICT helps achievements and outcomes, which was unbelievable for a huge range of its creators. Each day, there are new manifestations of ICT services. It seems that their influences are brought to all the world and people. E-commerce are discussed as one of the most important of these developments; and due to its increasing development, organizations have to use it optionally or based on special circumstances (Jorgenson \& Griliches, 1967; Jorgenson et al., 2000;

*Corresponding author.

E-mail addresses: baqi1341@gmail.com (A. Baghi Nasrabadi) 
Baghaei Ravari \& Moghadasi, 2007). Given the importance of e-commerce on the global economy and its significant growth, the necessity of using internet marketing in exports can be expressed as follows:

A direct relationship between buyer and seller without limitation of time and place, easy access to vast amounts of data, savings in time and space, reducing marketing costs compared to traditional marketing, universal access and customer-oriented, so that the use of Internet technology could facilitate pricing and designing for specifying characteristics of good on line (Holly Jr. \& Stumph, 2008). Given that the present study sought to examine the impact of e-commerce in developing exports of rose water and essences of Kashan, Iran to the United Arabic Emirates, to perform statistical tests and determine the level and type of relationship between the independent and dependent variables proportionate and corresponding to the purpose of the study, the research questions are as follows:

The main questions:

- Do information infrastructural factors and barriers to e-commerce influence on development of exports of rose water and essences of Kashan to United Arabic Emirates?

Sub-questions:

- Do human, educational, cultural and behavioral infrastructural factors and barriers to ecommerce influence on development of exports of rose water and essences of Kashan to United Arabic Emirates?

- Do legal and security infrastructural factors and barriers to e-commerce influence on development of exports of rose water and essences of Kashan to United Arabic Emirates?

- Do Financial and Software infrastructural factors and barriers to e-commerce influence on development of exports of rose water and essences of Kashan to United Arabic Emirates?

- Do technical and hardware factors and barriers to e-commerce influence on development of exports of rose water and essences of Kashan to United Arabic Emirates?

- Do factors and barriers of customs, trade and tax to e-commerce influence on development of exports of rose water and essences of Kashan to United Arabic Emirates?

- Do on-line factors and barriers to e-commerce influence on development of exports of rose water and essences of Kashan to United Arabic Emirates?

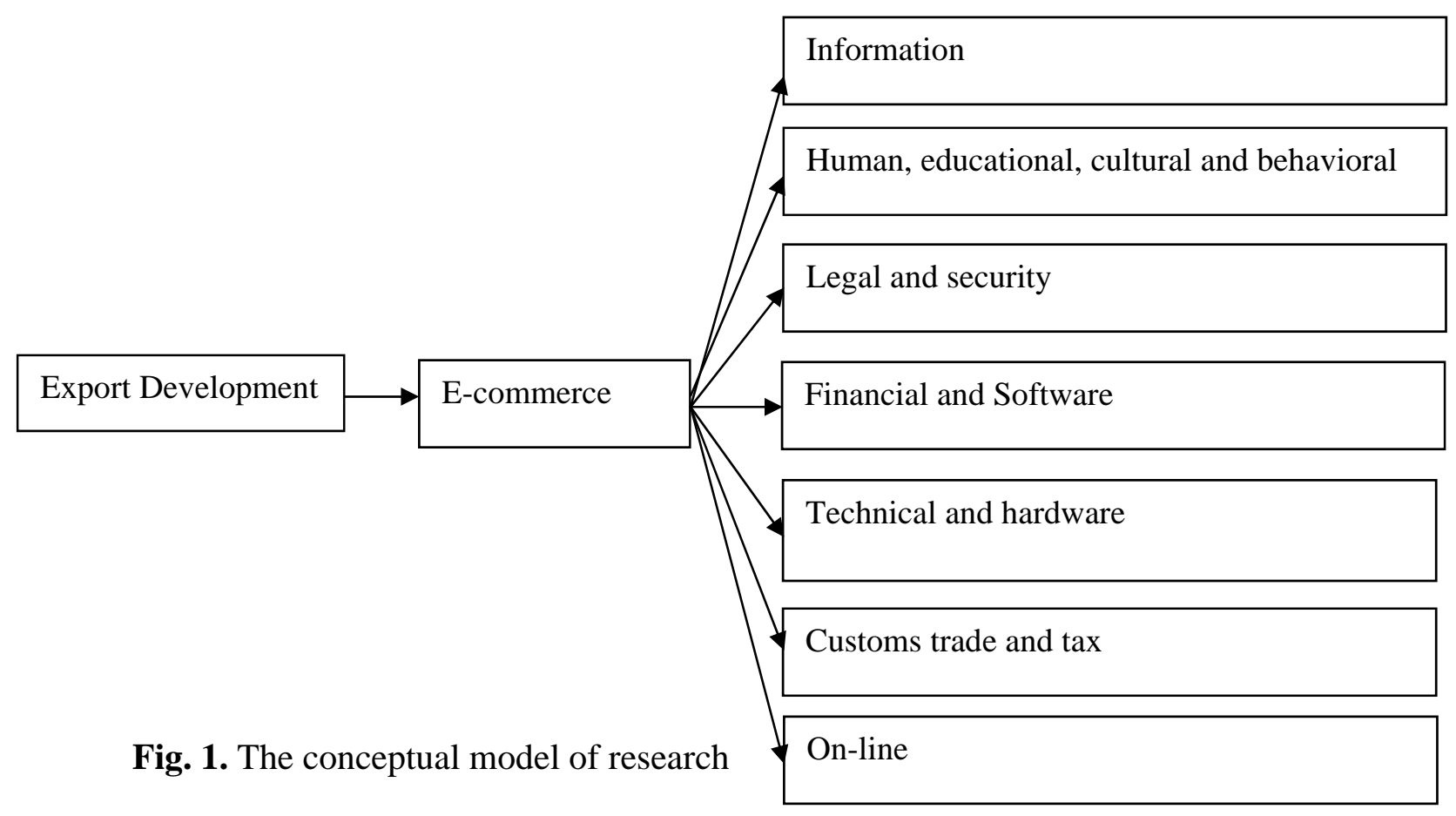




\section{Review of literature}

Electronic Commerce is performance of commercial activities with the use of computer communications networks, particularly the Internet (Coppel, 2000). Electronic Commerce is a paperless business. By e-commerce, information exchange for buying and selling and necessary information for the transportation of goods are prepared with less effort and banking transactions are executed faster (Colecchia, 2000). Companies to communicate with each other would not have present limitations; and their interrelationships are established easier and faster. Relationships between customers and vendors can be a one to one with each customer. In other words, electronic commerce is a generic name for a range of applications and systems that do services like looking for information, exchange management investigating the credit history, giving credit, on line payment, reporting and account management on the Internet (Berentsen, 1998). These systems provide the fundamental basis for Internet-based activities. The aim of implementation of electronic commerce is to offer a new way of doing business. Due to this method, traders are able to deliver their products and services all the time and to all the buyers around the world - regardless of their geographical borders and nationalities (A'rabi \& Sarmed Sa'idi, 2004). There are a lot of studies accomplished on infrastructure needed for e-commerce worldwide, which reveal some aspects of e-commerce infrastructure. They can be combined by a careful and detailed examination to create a comprehensive model of e-commerce infrastructure. Now, some of these studies will be considered. Some of the basic infrastructures of e-commerce are as follows (Sabagh Armani \& Esfidani, 2004; Salehi Sedighani \& Akhavan, 2005; Criscuolo \& Martin, 2009):

Network - Web Server- Web Server Support and Software- electronic catalog - web design and software for construction of systems, and interactive software in other aspects, infrastructure required for the development of e-commerce can be expressed as follows:

Reliable electric power - standard and qualified communication networks should have wide and suitable bandwidth for connecting companies and consumers, easy access to communication networks for consumers and employees of companies, internally integrated computer systems for companies with programs and standards for data storage in the way that it could be connected with business partners and consumers, standard computer facilities for accessing of employees and consumers, credit and banking facilities for companies and consumers, security systems, data storage and communication, technical expertise for the implementation and operation of e-commerce systems, appropriate transport infrastructure, Management commitment, efficient and convenient vision, assessment and improvement of internal and external business processes, prototype phasing for the implementation of electronic commerce. Other studies have also highlighted the following infrastructure (Khodadad Hseini \& Fathi, 2013):

\subsection{Information infrastructure}

It includes technology and standards. With the rapid development of technology and standards for ecommerce, developing countries do not have much to say. All development efforts in this area actually happened in developed countries. Global information infrastructure is the most important facilitator of Info E-commerce that third world countries should deal with it in order to develop the technical infrastructure (Brynjolfsson \& Hitt, 2000; Bruce \& Fox, 2001). The International Telecommunications Union is the most important international organization that has designed its standards. Despite the efforts of international organizations, developing countries, including Iran, should start local measures necessary for the implementation of appropriate technical infrastructure for e-commerce; but it has not done yet. This is a major barrier to the growth and development of ecommerce. 


\subsection{Legal infrastructure}

When designing e-commerce legal infrastructure, governments should take note that it would have very substantial impact on the country's trade performance. There are many problems that third world countries should consider in order to design and set up e-commerce law:

Promoting problems related to sexuality, racial malice, customer support, and copy and tax rights.

\subsection{Financial infrastructure}

One of the problems in third world countries is the issue of facilitating the flow of capital in the development of e-commerce financial infrastructure. Financial and Electronic Banking infrastructure design, in turn, requires measures such as security of documents, electronic signature, personal information security and trust, which have not been considered in Iran; and appropriate measures should be taken in this regard.

\subsection{Customs, tariffs and tax infrastructure}

However, by creating a virtual and electronic transfer of information, e-commerce will greatly improve the efficiency of business; but one of the most important problems is the lack of physical delivery of the products sold or exported, from the origins of customs and taxation. For this purpose, a method that has been set is tax based on the bit. That means the tax is calculated based on the data transfer rate. The problem with these tools is its extremely discriminatory nature; because there is no distinction between commercial and non-commercial transactions. However, there is no significant correlation between the amount of data transferred and the monetary value of the exchanged product. Taxes are discussed both in the national dimension and in the international level with special attention to the customs relations between the countries.

\section{Research Methodology}

This is an applied study. The descriptive research method is used. It is cross sectional. It is quantitative. Quantitative methods are used for data collection through the questionnaire. The population consists of the manufacturer and exporter of essences and rosewater in Kashan. The sample size includes 77 people. Due to the number of managers in every field, the questionnaires are distributed among the entire organization. With respect to the objectives and hypotheses of the study, factors related to information, human, educational, behavioral, legal, legal, security, financial, software, and hardware technical, customs, trade, taxation infrastructure as the variables are examined. In addition, the moderator variables examined in this study are gender, age, education level, field of study and work experience. For data collection, the library (Internet, books, articles and thesis and research reports) and field methods (questionnaire) is used. Library research methods are used to study the various aspects of theoretical and conceptual research, literature and background of research on the subject of research. In this study, field method is used to collect the necessary data for the statistical analysis of hypothesis including questionnaires distributed among employees of companies and exporter of essences and rosewater in Kashan. The questionnaire used in this study can be divided into two main questions asked by the public.

A) General question: here are five questions about the general characteristics of the respondents such as gender, age, marital status, education, and work experience.

B) Main questions:

In this questionnaire, five questions for assessing human, educational, cultural and behavioral infrastructure, five questions for legal, legal and security infrastructure, five Questions for financial and software infrastructure, five questions for hardware and technical factors, five Questions for, customs, trade and taxation infrastructure, five question for the online factor and five questions for information infrastructure were defined according to the hypotheses and the conceptual model and the 
literature to measure the variables. The validity of the method has been used for content validity. First, Questionnaires was given to a number of scholars and teachers of management and behavioral sciences including the supervisor and counselor; and they were asked about the questions and the evaluation of hypotheses. They confirmed it with Reforms needed.

\section{Findings}

In analytical study, more sophisticated procedures are used to analyze the data; but in the descriptive study, it is enough to describe aspects of phenomena and to analyze characteristics of the population and the community studied superficially or completely. However, in both cases, the required statistical data is analyzed. In this section, the data related to General characteristics of respondents tested such as gender, age, work experience and educational background are described.

- Gender: the questionnaire had been distributed to 77 companies, manufacturer and male exporters.

- Age: according to findings, age group of 30 to 45 years with 46 people frequency representing more frequency than the other groups. People under the age of 30 years and 50 years are 8.33\% and 5.6\% of the whole population, respectively.

- Education: The highest percentages of people tested in this study are the respondents with BA degree $(57.53 \%)$ and the lowest are the respondents with diploma, which include $8.7 \%$ of respondents.

- Work experiences: The highest frequency belongs to 5 to 10 years of experiences with 41.56 percent; but percentages of frequency for groups with less than 5 years of work experience, 5 to 10 years of experiences and 15 years are $8.22 \%, 58.15 \%$ and $78.20 \%$, respectively.

In this section, according to data obtained from samples and by using statistical tests, the hypotheses are tested. Before, having tested the hypotheses of the study, the researcher did Kolmogorov-Smirnov test for getting information on the distribution of statistical data and its results showed that the data were normally distributed. The answers to all the questions in the questionnaire given by the sample are used to perform the test and answer the research question. The given scores to responses: very low, low, medium, high and very high in the encoded data, are 1, 2, 3, 4 and 5 respectively according to Likert scale. According to the research question, to test the hypothesis, Pearson's correlation coefficient is used to test a significant relationship between qualitative variables in order to show whether Information, human, social, educational, cultural, behavioral, legal, legal, security, and financial software, hardware and technology, customs, trade and taxation infrastructure have a role in development of exports of rose water and essences of Kashan to United Arabic Emirates or no. Testing this hypothesis becomes the statistical hypotheses (Representing claims and conflicting claims).

\section{Table 1}

Results of t-test for the hypothesis of the study

\begin{tabular}{|c|c|c|c|c|c|c|c|}
\hline Variable & Lower limit & High limit & $(\mathrm{SD})$ & mean & Sig. & $\mathrm{t}$ & df \\
\hline Human infrastructure & 0.1832 & 0.3346 & 0.71076 & 3.2581 & 0.000 & 6.726 & 264 \\
\hline Legal and security infrastructure & 0.2021 & 0.3765 & 0.81838 & 3.2653 & 0.000 & 4.527 & 264 \\
\hline Financial and software infrastructure & 0.2739 & 0.4583 & 0.56359 & 3.0661 & 0.000 & 7.849 & 264 \\
\hline Technical and hardware factors & 0.2021 & 0.3465 & 0.81738 & 3.1325 & 0.000 & 6.432 & 264 \\
\hline Customs trade and tax factors & -0.0772 & 0.3349 & 0.78500 & 3.194 & 0.000 & 3.161 & 265 \\
\hline Online factors & 0.0888 & 0.2574 & 0.79129 & 3.1731 & 0.000 & 4.040 & 264 \\
\hline Information infrastructure & 0.2867 & 0.4497 & 0.76512 & 3.3482 & 0.000 & 8.887 & 264 \\
\hline
\end{tabular}

According to Table 1, the correlation coefficient observed are significant in the $\mathrm{P}<0.05$ for all assumptions, statistical hypothesis $\mathrm{H}_{0}$ is rejected and alternative hypothesis $\mathrm{H}_{1}$ is confirmed. Therefore, with 95\% confidence, we can examine the research hypotheses: 
First hypothesis: From the view of experts, Information, human, social, educational, cultural, behavioral, legal, legal, security, and financial software, hardware and technology, customs, trade and taxation infrastructure have a role in development of exports of rose water and essences of Kashan to United Arabic Emirates.

About the rest, with 95\% confidence, we can confirm the research hypotheses. Friedman test is used to rank barriers in electronic commerce and exports of rose water and essences in Kashan. The results are shown in Table 2. As we can see in this table, information infrastructure and problems are in the first order with mean scores 5.68 and problems related to financial and software infrastructure is in seventh order. The other barriers are given as follows,

\section{Table 2}

Results of Friedman test to rank barriers and problems of exports

\begin{tabular}{lll}
\hline Variables & Mean & rank \\
\hline Customs trade and tax factors and infrastructure & 3.51 & 4 \\
Legal and security infrastructure & 4.17 & 2 \\
information infrastructure & 4.68 & 1 \\
Technical and hardware factors & 2.10 & 6 \\
Human and educational infrastructure & 4.16 & 3 \\
Online infrastructure in Iran & 2.37 & 5 \\
Financial and software infrastructure & 2.06 & 7 \\
\hline
\end{tabular}

\section{Conclusion}

According to the findings and results of statistical tests and other findings, for the company manufacturing rose water and herbal essences, the following cases are recommended:

- Based on the findings of the study (all questions) which showed infrastructures and its components have impact on electronic commerce of rose water and herbal essences, it is recommended to company officials to define human resources unit in comparison with preferred units of the company for the formation of the company's organizational structure and dimensions and consider great authority for the unit in policy and decision-making of the company.

- The findings of the first sub-question shows that human, educational, cultural, and behavioral factors and infrastructure barriers have important roles in development of exports of rose water and essences of Kashan to United Arabic Emirates. Discussion of trust is one of the most important issues involved in export, which has increased because of the measures taken in the development of exports. It is also because of the measures taken such as the formation of cooperatives, development of industrial tours, educational programs and exhibitions of the level of social capital. This leads to increased levels of competition, less use of adulterated essence production (which was considered as one of the weaknesses of the cluster), and partly causes the deletion of the middleman in exports. (Though in some parts the presence of the intermediaries can be seen), so Discussion of training is very important.

- The findings of the second sub-question show that legal and security factors and infrastructure barriers played important roles in development of exports of rose water and essences of Kashan to United Arabic Emirates. For this purpose, executive Strategies are recommended for the removing legal and Security barriers. They may consider Fair laws approved by Congress, correct bill prepared by the government, focus on electronic government on organizational body, prepare and standardize the rules and regulations of the EC and export of rose water and herbal essence. They may also consider heavy penalties for violations of rules and regulations, compilation of stable rules to reduce all types of risks and implement laws completely. 
- The findings of third sub-question shows that financial and software factors infrastructure of Ecommerce played important roles in development of exports of rose water and essences of Kashan to United Arabic Emirates. Among such indicators such as employment, financial investment, exports, production capacity and health levels of production, financial investment have maximum development in cluster project. That is, in the period from 2007 to 2010, we saw an increase of 745 units in employment.

- The findings of the fourth sub-question shows that technical and software factors infrastructure of Ecommerce played important roles in development of exports of rose water and essences of Kashan to United Arabic Emirates. Enhancement in the level of technology and utilization of new hardware and devices are considered as important determinants of export promotion. Utilization of modem equipment can increase production both in terms of product variety and production capacity; it can also increase export capacity for Export Company.

- The findings of the fifth sub-question show that customs trade and tax factors and infrastructure of Ecommerce played important roles in development of exports of rose water and essences of Kashan to United Arabic Emirates. Implementing strategies to eliminate tariff, trade and tax barriers including both the planning and scheduling problems in this area in the short, medium and long term, improving trade and customs laws, due to problems and modification of existing laws, are recommended for developing exports of rose water and herbal essence. Managers of these units may also use the experiences of leading countries in the field of customs and tax commercial infrastructure, elimination of exclusive customs system, improving the system of customs, elimination of trade barriers and the development of foreign trade in the export of rose water and herbal essence.

- According to the results of the sixth sub-question, online factors played important roles in development of exports of rose water and essences of Kashan to United Arabic Emirates. The results show that the mean for online factor in development of exports of rose water and essences of Kashan to United Arabic Emirates is lower than average. Thus, it can be claimed that online factor had no effect on development of exports of rose water and essences of Kashan to United Arabic Emirates. There are some executive strategies recommended including investment and creating the necessary technical background and development of the Internet and the availability of high speed Internet for all users, cheaper of Web services by telecommunication and related equipment, the development and use of wireless technologies such as ADSL lines and Wimax to solve problem related to the Internet. - According to the findings of the analysis of the seventh question, factors and barriers to information infrastructure of E-commerce played essential role roles in development of exports of rose water and essences of Kashan to United Arabic Emirates. These hypotheses were confirmed by using one sample t-test. It is therefore recommended to use high actions and experiences of skilled experts to remove the barriers and to use experience and successful performance of the developed countries of the EC to create opportunities for existing talent. In addition, providing easy access to computer equipment and development of IT systems operated by the government will be highly effective.

- In addition to the above suggestions, the following items are generally recommended:

There will be many benefits for stakeholders, if the agro-industry, which was started by the government, are followed up and operated. One of the advantages is healthy competition for highquality production and dumping of products, knowledge of the prices of raw materials and different products, purchase of material for the network, distribution and sale of products through a network of distributors and sales to far from area, knowledge of the methods and devices of new generation, possibility of exports through export consortia. Unfortunately, this plan failed due to lack of funds from the government and lack of cooperation from the stakeholders and producers. Now with regard to the advantages mentioned, it is recommended to government, stakeholders and producers to follow 
this plan more strictly, until the desired result is achieved. Because of the many benefits associated with industrial production in this cluster, including an increase in the production and sale of various products as well as healthy possible types of essences and rose water, etc., If there is no resistance from the traditional units to industrialization, these units can use the above advantages as well they can produce essence which have higher valued and are economically justified in comparison with other products; and finally they can make more money.

Based on research findings, marketing played an important role in introducing better cluster products and better access to new markets. However, these measures in Iran are limited to participating in several exhibitions of food industries in the adjacent provinces. The importance of marketing and the use of new techniques at home and especially abroad will increase sales and revenue of producers as well as introducing better cluster products. It is recommended to the managers to increase the level of their production both quantitatively and qualitatively by alternate and updates training and showing interest in learning new methods of production. According to the importance of the new industrial clusters in Iran, researchers can study its various topics, such as how to utilize and enhance technology in different clusters, marketing and management of small and medium firms.

\section{References}

A'rabi, M., \& Sarmed Sa'idi, S. (2004), Evaluation of environmental barriers and providing a suitable model for e-commerce in Iran, Information Sciences, 18(1,2). (In Persian).

Baghaei Ravari, M., \& Moghadasi, A. (2007). A three dimensional model of the challenges in implementing e-commerce in Iran. Journal of Knowledge and Development, 1 (In Persian).

Berentsen, A. (1998). Monetary policy implications of digital money. International Review of Social Science (Kyklos), 51(1), 89-117.

Bruce, D. J., \& Fox, W. F. (2001). State and local sales tax revenue losses from e-commerce: Updated estimates. Knoxville, Tennessee: Center for Business and Economic Research.

Brynjolfsson, E., \& Hitt, L. M. (2000). Beyond computation: Information technology, organizational transformation and business performance. The Journal of Economic Perspectives, 14(4), 23-48.

Colecchia, A., Pattinson, B., \& Atrostic, B. (2000). Defining and measuring electronic commerce. Document de discussion de la DSTI/OCDE.

Coppel, J. (2000). E-commerce: impacts and policy challenges (No. 252). OECD Publishing.

Criscuolo, C., \& Martin, R. (2009). Multinationals and US productivity leadership: evidence from Great Britain. The Review of Economics and Statistics, 91(2), 263-281.

Holly Jr, P., \& Stumph, C. (2008). The effect of technology growth on money supply and demand: A cointegration approach. The Park Place Economist, 5.

Jorgenson, D. W., \& Griliches, Z. (1967). The explanation of productivity change. The Review of Economic Studies, 34(3), 249-283.

Jorgenson, D. W., Stiroh, K. J., Gordon, R. J., \& Sichel, D. E. (2000). Raising the speed limit: US economic growth in the information age. Brookings papers on economic activity, 2000(1), 125235.

Khodadad Hseini, H., \& Fathi, S. (2013). A method for prioritizing Iranian industries based on the ability of international market makers and e-commerce. Journal of Business Research, 25.

Kiley, M. T. (1999). Computers and growth with costs of adjustment: will the future look like the past? (Vol. 99, No. 36). Divisions of Research \& Statistics and Monetary Affairs, Federal Reserve Board.

Report of the High Council of Informatics (2001). Feasibility Report and e-business policies of the Islamic Republic of Iran: Approved specialized information, (In Persian).

Salehi Sedighani, J., \& Akhavan, M. (2005). Business models among the firm's e-commerce, controller (In Persian).

Sabagh Armani, M. \& Esfidani, M.H. (2004). Study of competitive impact of globalization and electronic commerce, (In Persian). 